\title{
INFLUENCING FACTORS ANALYSIS TO DETERMINE STANDARD TIME OF OPERATORS IN A GAUGE CALIBRATION PROCESS
}

\author{
Karen Botelho Faria \\ Universidade Candido Mendes, Brazil \\ E-mail: karenbotelhofaria123@gmail.com
}

Ana Carla de Souza Gomes dos Santos Instituto Federal do Rio de Janeiro, Brazil E-mail: anacarla.engenharia@gmail.com

Layanne Andrade Mendonça Instituto Federal Fluminense, Brazil E-mail: layanne.mendoca@iff.edu.br

Augusto da Cunha Reis CEFET, Brazil

E-mail: augusto@aaa.puc-rio.br

Sérgio Augusto Faria Salles Instituto Federal Fluminense, Brazil

E-mail: safsalles@hotmail.com

Submission: 29/03/2018 Accept: 29/03/2018

\section{ABSTRACT}

Companies seek to improve service level, aiming to meet the most demanding customers that enable it survives in a complex and competitive marketplace. The article presents a study in a company of repair and maintenance of industrial equipment and instruments, located in Campos dos Goytacazes (RJ), aiming to identify the factors that influence the execution time of the operators' activities in the manometer calibration process. For this scope, the study of times and movements and statistical analyzes, such as Linear Regression and ANOVA, were applied. The survey revealed that operators who have completed their technical courses in mechanics perform the activities in standard time greater than those who have not yet completed and that working on board and being married do not change the execution time. 
It also revealed that employees of lower age and longer experience are preferable because of shorter operating times and that the age was statistically significant, revealing that the most appropriate age to have a shorter time is approximately 27 years.

Keywords: time-motion study; productivity; regression; ANOVA

\section{INTRODUCTION}

Service sector has faced a decrease of $3.2 \%$ on volume of services rendered in July 2017 in comparison with the same month a year ago and a decrease of $0.8 \%$ in comparison with its previous month (IBGE, 2017). As a result, companies at a high level of competitiveness are aiming to meet customer requirements and remain survivor in the marketplace.

Some standardization tools such as time and motion study (TMS), first proposed by Frederick Taylor, provides competitiveness for a company and is still currently applied in several organizations (NOVASKI; SUGAI, 2002; SILVA; GUIMARÃES; VERALDO JÚNIOR, 2014; SIMÕES; FENNER; ESPERANCINI, 2014). This study enables reduction of the cycle time, best control over the process, standardization of the way of work and an increase in production capacity in view of encouraging competitive differentiation.

According to Figueiredo, Oliveira and Santos (2011), time and motion study is applied in order to eliminate unnecessary efforts when performing a given operation by establishing a certain way to perform it and thus obtain methods to assure an overall improving of the process.

By applying TMS it is also possible to identify which operators are performing the activities above or below the value established by the company (SANTOS et al., 2015). However, it is extremely important to find out what are the factors that influence this performance time. This sort of analysis is possible through statistical techniques, such as ANOVA (for qualitative data) and Linear Regression (for quantitative data).

Therefore, the aim of this article is to provide an application of time and motion studies to identify the factors that influence the execution time of the activities performed by the operators. The study was carried out in a company that provides 
INDEPENDENT JOURNAL OF MANAGEMENT \& PRODUCTION (IJM\&P)

http://www.ijmp.jor.br

v. 9, n. 5, Special Edition IFLOG 2017

ISSN: 2236-269X

DOI: 10.14807/ijmp.v9i5.811

equipment repair, maintenance and repair service according to NR-13, located in Campos dos Goytacazes, specifically in the calibrating gauge process.

This paper is structured in five sections as follows. Section 1 is the introductory one in which the article is contextualized. Section 2 reviews time and motion study key concepts in which the study is based on. In Section 3, the methodology proposed for the study is described. The results and subsequent discussions are provided in Section 4 and, finally, the paper is concluded in Section 5.

\section{TIME AND MOTION STUDY}

According to Chiavenato (2014) and Santos et al. (2015), time and motion studies were first suggested in 1881 by Frederick Taylor while working at the Midvale Steel Company. After becoming chief operating engineer, he decided to change the management system in a way that the interests of both factory floor workers and high managers would not conflict.

Soon, he realized that the great obstacle was the unfair workload given to the workforce and got permission to apply a certain amount of money in a scientific study in order to determine the best production time. He chose two healthy and efficient workers and aimed to find out what a "fair day's work" meant for an efficient worker; i.e., the best way a man could do his job year after year successfully.

Thus, Taylor discovered that the energy spent during the execution of heavy jobs were correlated with its rest periods, frequencies and durations and also established that there would always be a faster method and a better instrument to be found and improved by means of scientific analysis and time/motion study.

Barnes (2004) indicates that time and motion study is used to determine the time required for a properly trained and qualified operator perform a specific task as well as its most appropriate execution method. Moreover, he states that time and motion study has the following purposes: (i) to find the most appropriate method for performing a task, (ii) standardize this method, (iii) determine the time taken by a given operator to perform the task at a normal pace, and (iv) guide and train the operator in the chosen method.

According to Peinado and Graeml (2007), time and motion studies are not only applied to define a better way of perform a task, but also to determine the 
productive capacity of an organization and elaborate production and cost reduction programs, among other applications.

For the work to be executed in a better and more efficient way, it must be analyzed under a specific method. The first step is to breakdown the operation into smaller and observable elements. Then, the number of repetitions is defined and the operator's time for each element is measured and recorded using a stop watch. This analysis is used to determine the performance time of the overall productive process, each task and each operator (CHIAVENATO, 2014; SANTOS et al., 2015). The observed time is relevant if the time to be measured exceeds five seconds. Thus, with the assistance of a stop watch, each step is timed several times so that the arithmetic mean can be calculated (JACOBS; CHASE, 2012).

After that, it is necessary to calculate the number of cycles $(N)$, so the number of elements collected in the study is valid and it can arrive at an accurate average time. In other words, the formula determines the minimum number of repetitions. A number greater than or equal to the value provided by the formula is statistically feasible and the average time found can be used. Equation 1 determines the minimum sample number:

$$
N=\left(\frac{Z . R}{E_{.} \cdot d_{2} \cdot \bar{X}}\right)^{2}
$$

Where:

$\mathrm{N}$ : Number of cycles;

Z: Standard normal distribution coefficient;

R: Sample's range;

Er: Relative error;

$d_{2}$ : Coefficient related to number of times previously observed;

$\bar{X}$ : Arithmetic mean of observed times.

It is acceptable to use a confidence interval between 90 and $95 \%$ to determine the standard normal distribution coefficient $(Z)$, and the relative error $(\mathrm{Er})$ with a margin between 5 and $10 \%$. The values of $Z$ and $d_{2}$ are set out in Tables 1 and 2 respectively: 
DOI: 10.14807/ijmp.v9i5.811

Table 1: Standard normal distribution coefficient $(Z)$

\begin{tabular}{ccccccccccc} 
Probability & $\mathbf{9 0 \%}$ & $\mathbf{9 1 \%}$ & $\mathbf{9 2 \%}$ & $\mathbf{9 3 \%}$ & $\mathbf{9 4 \%}$ & $\mathbf{9 5 \%}$ & $\mathbf{9 6 \%}$ & $\mathbf{9 7 \%}$ & $\mathbf{9 8 \%}$ & $\mathbf{9 9 \%}$ \\
\hline $\mathbf{Z}$ & 1.65 & 1.70 & 1.75 & 1.81 & 1.88 & 1.96 & 2.05 & 2.17 & 2.33 & 2.58 \\
\hline
\end{tabular}

Table 2: Coefficient related to number of times previously observed

\begin{tabular}{cccccccccc}
\hline $\mathbf{N}$ & $\mathbf{2}$ & $\mathbf{3}$ & $\mathbf{5}$ & $\mathbf{5}$ & $\mathbf{6}$ & $\mathbf{7}$ & $\mathbf{8}$ & $\mathbf{9}$ & $\mathbf{1 0}$ \\
\hline $\mathbf{d}_{\mathbf{2}}$ & 1.128 & 1.693 & 2.059 & 2.326 & 2.534 & 2.704 & 2.847 & 2.970 & 3.078 \\
\hline \multicolumn{8}{c}{ Source: Adapted from Peinado and Graeml $(2007)$} &
\end{tabular}

The next step is to calculate the performance rating of each operator using the average time of the productive process, called observed time (OT), and the average time of each operator, called normal time (NT). OT is equivalent to a normal rate of $100 \%$. Therefore, the speed of each operator is calculated by the Equation 2 below:

$P R=\frac{N T}{O T}$

Where:

NT: Normal Time;

OT: Observed Time;

$P R$ : Performance rating of each operator.

There are some reasons that may lead the worker to be at an above-standard rate, for example: fatigue, lack of practice, family problems, lack of motivation, company time, inadequate training or lack of training, age, work environment and so on. Thus, the performance rating calculation reveals whether the operator is: slow (above 100\%); fast (below 100\%); or in the ideal time (equal to 100\%).

According to Martins and Laugeni (2015), it is impossible for an operator to work all day without interruption or break. Thus, breaks during working hours are granted to workers so that they can meet their physiological and personal needs, thereby minimizing their fatigue and even resulting in increased productivity when they return to their jobs. Allowances or tolerance $(p)$ is made by means of the sum of time that the company grants its employees, including time for delays and alimentation, due to the workload according to Equation 3 below:

$p=\frac{\sum \text { Break time }}{\text { Toal shift work time }}$ 
After calculating the allowance time (p), the tolerance factor (TF) is calculated by Equation 4 below:

$T F=\frac{1}{1-p}$

Where:

TF: Tolerance factor;

p: Allowances.

The tolerance factor (TF) obtained is added to the OT and NT of each operator, resulting in the standard time (ST), according to Equations 5 and 6 below:

$S T_{\text {Organization }}=O T \times T F$

$S T_{\text {operator }}=N T \times T F$

Where

$S T=$ Standard time;

$N T=$ Normal Time;

$T F=$ Tolerance factor;

OT= Observed Time.

These two calculations differ from each other since the calculation of the ST of the operator is the multiplication of the NT by the TF. The standard time of the company is calculated by multiplying the OT by the TF.

\subsection{Linear regression and time and motion study}

According to Golberg and Cho (2004), the regression analysis consists of obtaining an equation that tries to explain the relationship among variables. In order to establish an equation that represents this analysis, it is necessary to draw a graph, called a scatter diagram, in order to verify how the values of the criterion variable $(Y)$ depends on the variation of the independent variables $(X)$.

It is observed whether the points in the diagram drawn fit the model line. For the study to be consistent, the model chosen must match what happens in practice, containing only the factors that are relevant to the explanation of the phenomenon. The linear regression models can be, among others, first degree or second degree, as shown in Equations 7 and 8, respectively:

$Y_{i}=\beta_{1} X_{i}+\beta_{0}+e_{i}$ 
Where:

$Y_{i}$ is the value observed at the $\mathrm{i}$-th level of variable $\mathrm{X}$;

$\beta_{1}$ is the regression coefficient;

$\beta_{0}$ is the constant of the regression;

$X_{i}$ is the $i$-th level of variable $X$;

$\mathrm{e}_{\mathrm{i}}$ is the error associated with the difference between the observed value and the estimated value for the same level $i$ of the variable $X$.

This model is a first-degree polynomial function whose graph is a straight line. The positive coefficient $\beta_{1}$ indicates that the function is increasing, i.e., increasing the levels of the variable $X$ studied, the response variable is also increased. However, if the regression coefficient is negative, it means the lower the factor level, the higher the response variable according to Equation 8 below:

$Y_{i}=\beta_{2} X_{i}^{2}+\beta_{1} X_{i}+\beta_{0}+e_{i}$

Where:

$\mathrm{Y}_{\mathrm{i}}$ is the value observed at the $\mathrm{i}$-th level of variable $\mathrm{X}$;

$\beta_{1}$ and $\beta_{2}$ are the regression coefficients;

$\beta_{0}$ is the regression constant;

$\mathrm{X}_{\mathrm{i}}$ is the $\mathrm{i}$-th level of variable $\mathrm{X}$;

$\mathrm{X}_{\mathrm{i}}^{2}$ is the $\mathrm{i}$-th level of variable $X$ squared;

$\mathrm{e}_{\mathrm{i}}$ is the associated error that means the difference between the observed value and the estimated value for the same level $i$ of the variable $X$.

The adjustment of the regression by a second-degree model occurs when the data do not behave around a line but a parabolic curve.

The process of identifying the optimal level of the factor that generates a greater or lesser value of the dependent variable is called optimization. A first-degree model with a positive coefficient, adjusted for a given range of factor levels, has a higher response value for the higher factor level of this interval. If the regression coefficient is negative, the highest value of the response variable is obtained using the lowest level of the factor studied.

A second-degree model, whose graph is a parabola, will have a maximum value if the coefficient $\beta_{2}$ associated with the quadratic term is negative. Otherwise, 
the adjusted equation will have a minimum value. The optimization process of this model occurs through the identification of the value of the level of the factor that maximizes or minimizes the dependent variable, denoted $\mathrm{x}_{\mathrm{v}}$ and calculated by Equation 9:

$x_{v}=-\frac{\beta_{1}}{2 \beta_{2}}$

To determine the maximum or minimum value of the dependent variable, the $\mathrm{x}_{\mathrm{v}}$ factor must be simply replaced in the adjusted equation.

The coefficient of determination $\mathrm{R}^{2}$ is a fundamental parameter in determining the best adjusted model. This can have a value between 0 and 1 and the closer it is to 1 , the better the model explains the variation of the data. If $R^{2}$ is close to 0 , it implies that there are other causes that did not enter the model, but should be studied or that another model should be adjusted.

By associating the application of linear regression to time and motion study, it is possible to identify which are the factors that affect the execution time of the operators. Each operator has an average time to perform the task, however when calculating the standard time of the operator and comparing it to the standard time of the company, it is concluded that some operators are slow and others are faster.

According to Peinado and Graeml (2007), the determination of the performance rating or rhythm of the worker is the most important and difficult detail of time study. Velocity was previously calculated subjectively by a specialist. Barnes (2004) confirms that the professional assigned to the timing when recording the survey data was responsible to evaluate the performance rate of each operator in relation to its normal speed reference in a personal way, not taking into account the variables that may affect the performance of the operator, such as family problems, execution time of the task to be studied, adequate training, pressure of superiors, among others.

\section{RESEARCH METHODOLOGY}

This section describes the research method adopted in this paper so that all steps can be replicated in future studies. 


\subsection{Data collection}

As highlighted by Amato and Reis (2016) a case study methodology allows an investigation of current events in a practical and holistic way in which the researcher has little or no control over the object in question. The research is classified according to its nature, since it aimed to generate new knowledge from a local practical application. To achieve this objective, this research is a case study which was conducted taking into account the unit of analysis that is the calibration process of manometers.

Regarding the approach, the research is characterized as both quantitative and qualitative, since it covered variables that were translated into numbers and has subjective characteristics. From the point of view of the objective, the research is classified as explanatory, because "it aims to identify the factors that determine or contribute to the occurrence of the phenomena" (SILVA; MENEZES, 2005).

Initially, a research was done on the topics that this article possesses so that the reader could clearly understand its purpose. After, the study object was chosen. The chosen process was the calibration of manometers based on the great representation that this operation has in the company's revenue.

Then, a survey, a division of the activities that compose the calibration of a manometer and the selection of five operators were made. This selection was made at random, according to company availability. Therefore, eight visits were made in loco, being five in the month of September and three in the month of November of 2016, for the accomplishment of the timekeeping.

\subsection{Data processing and analysis}

The stages related to time and motion study were performed: operators' activities time were recorded using a stopwatch and a drawing board; observed time (OT) were calculated to each small operation and to the overall production process; normal time (NT) and performance rate of each operator were defined; tolerance factor (FT) was determined; and finally, standard time (TP) was calculated. In view of the variability of the operators' times, it became impossible to calculate the number of cycles.

The data were submitted to statistical analysis aiming to identify the factors, or independent variables that may interfere with the standard time response variable of 
the operators. Assuming normality, data independence and homogeneity of variance, an Analysis of Variance (ANOVA) was performed with qualitative levels factors. In this situation, it was intended to know whether the factors such as completed technical mechanical course, children, marital status and/or work situation, influence operators' performance. Each factor has two qualitative levels, described in the table below:

Table 3: Qualitative levels

\section{Factors}

\begin{tabular}{|c|c|c|c|c|c|c|c|}
\hline & \multicolumn{2}{|c|}{ Married } & \multicolumn{2}{|c|}{ Children } & \multicolumn{2}{|c|}{ Work situation } & Education \\
\hline Leve & Yes & No & Yes & No & Onshore & Offshore & Complete \\
\hline
\end{tabular}

The hypotheses of interest in an ANOVA are as follows:

$$
\left\{\begin{array}{l}
H_{0}: \mu_{1}=\mu_{2} \\
H_{1}: \mu_{1} \neq \mu_{2}
\end{array}\right.
$$

In this formula, $\mu 1$ stands for the mean of the "yes" or "completed" level of the factor under analysis and $\mu 2$, stands for "no" or "not completed" level. If the p-value calculated is lower than the established level of significance ( $\alpha$ ), the hypothesis of equal means is rejected; thus, a difference between factor levels is detected. This means that changing the "yes" to "no" or "completed" to "not completed" level of the factor under analysis causes change in the standard time.

The results were interpreted comparing the averages of the studied levels. Those with lower values were recommended, indicating a shorter activity operating time.

For the quantitative analysis, the standard time was used as dependent variable as a function of the factors of experience, age and quantity of children of the operators. The table below presents the factors and their respective levels used in the analysis:

Table 4: Experience time, age and number of children Factors

\begin{tabular}{cccc} 
& Experience time (months) & Age (years) & Number of children \\
\cline { 2 - 4 } Levels & 18 & 20 & 0 \\
& 24 & 23 & 1 \\
& 30 & 32 & 2 \\
36 & 33 &
\end{tabular}

Correlation analysis was used to analyze the strength of the relationship between the factors and the standard time. Subsequently, a first degree or second degree linear regression adjustment was made. For the factors that were statistically 
significant ( $p$-value $<\alpha)$ in the fit of the first-degree model, an adjustment for a second-degree model was then made, since they could have a parabolic behavior. The model with highest coefficient of determination $\left(R^{2}\right)$ was the one defined as the best represent of the situation, indicating that this model explains better the variation of the data collected.

For the adjustment of the first-degree and quadratic linear equations, the models represented in Equations 7 and 8 were used respectively. For the seconddegree adjustments, the optimization was done by calculating the value of the vertex of the parabola $\left({ }^{x_{v}}\right)$ that generates a better standard time. This value was calculated using Equation 9.

For all analyzes, the significance level was defined as $5 \%(\alpha=0.05)$ and Microsoft Office Excel and Statistica 7.0 were used.

\section{RESULTS AND DISCUSSION}

The research was conducted in a company that provides inspection, maintenance and calibration services of industrial equipment and instruments, focused on safety and technology improvement for more than 17 years, helping companies to achieve excellence in operation performance. The company is located in Campos dos Goytacazes/RJ and currently has 88 employees.

Time and motion study was performed and the calibration time of the manometer was measured considering five employees who were observed during the process.

Calibration time included the time the manometer is put into the calibration pump until its final phase, which is the photo and labeling stage. After placing the pressure gauge on the pump, the calibration process occurs as follows:

- The pressure gauge is installed in the pump: the operator installs the pressure gauge on the pump, checks for any type of leakage and waits for Bourdom to settle by injecting and withdrawing pressure, while it begins to fill its certificate with the equipment code and its pressure;

- 1st Calibration cycle: this is where the operator handles the pump so that it injects pressure into the pressure gauge, which will cause the pressure indicators to appear according to the progress of the 1st cycle; 
- 2nd calibration cycle: this cycle is only performed to check the values obtained in the first cycle;

- Finalization of the certificate: in this step, the operator transcribes for the certificate the values found and calculated and also checks if the data put in the certificates are correct and;

- Instrument finalization: the operator places a label on each gauge containing the calibration date and its validity, which is 3 months, in addition to placing the instrument code. Photographs of all calibrated manometers are also taken for archiving and controlling processes. These photos go along with the certificate for the clients.

\subsection{Work measurement}

For each activity, five manometers and five operators were used. For each activity of the calibration process, there is a legend used to simplify the interpretation of the table below: $\mathrm{A} 1$ (manometer installation at pump), A2 (1st calibration cycle), A3 (2nd calibration cycle), A4 (certificate completion) and A5 (finalization of the instrument). In addition, it follows the NT for each operator.

Table 5: Normal time for each operator

\begin{tabular}{cccccc|c}
\hline A1 & C1 & C2 & C3 & C4 & C5 & NT (s) \\
\hline Operator 1 & 164 & 120 & 86 & 95 & 136 & 120.2 \\
Operator 2 & 223 & 140 & 160 & 180 & 147 & 170.0 \\
Operator 3 & 138 & 143 & 107 & 105 & 114 & 121.4 \\
Operator 4 & 160 & 120 & 136 & 141 & 132 & 137.8 \\
Operator 5 & 135 & 110 & 114 & 115 & 116 & 118.0 \\
A2 & & & & & & \\
Operator 1 & 88 & 92 & 72 & 85 & 76 & 82.6 \\
Operator 2 & 120 & 142 & 82 & 121 & 124 & 117.8 \\
Operator 3 & 94 & 89 & 77 & 109 & 90 & 91.8 \\
Operator 4 & 86 & 83 & 75 & 80 & 75 & 79.8 \\
Operator 5 & 74 & 74 & 75 & 81 & 76 & 76.0 \\
A3 & & & & & & \\
Operator 1 & 83 & 64 & 63 & 70 & 63 & 68.6 \\
Operator 2 & 85 & 106 & 140 & 95 & 119 & 109.0 \\
Operator 3 & 95 & 67 & 70 & 119 & 120 & 94.2 \\
Operator 4 & 101 & 77 & 69 & 76 & 79 & 80.4 \\
Operator 5 & 60 & 66 & 60 & 82 & 62 & 66.0 \\
A4 & & & & & & \\
Operator 1 & 43 & 39 & 40 & 43 & 46 & 42.0 \\
Operator 2 & 52 & 39 & 60 & 70 & 74 & 59.0 \\
Operator 3 & 73 & 73 & 41 & 48 & 49 & 56.8 \\
Operator 4 & 42 & 65 & 70 & 44 & 46 & 53.4 \\
Operator 5 & 50 & 58 & 56 & 57 & 55 & 55.2 \\
A5 & & & & & & \\
Operator 1 & 90 & 122 & 80 & 60 & 35 & 77.4 \\
Operator 2 & 90 & 69 & 100 & 99 & 106 & 92.8
\end{tabular}


DOI: 10.14807/ijmp.v9i5.811

\begin{tabular}{llllll|l} 
Operator 3 & 51 & 43 & 38 & 50 & 37 & 43.8 \\
Operator 4 & 48 & 43 & 46 & 45 & 44 & 45.2 \\
Operator 5 & 39 & 40 & 42 & 38 & 37 & 39.2 \\
\hline
\end{tabular}

Table 6 shows the OT of each activity of the manometer calibration process and the OT of the overall production process.

Table 6: Average time of activities and production process

\begin{tabular}{ccc}
\hline Activities & OT of operation(s) & OT of overall production process \\
\hline A1 & 133.5 & \\
A2 & 89.6 & 419.7 \\
A3 & 83.6 & \\
A4 & 53.3 & \\
A5 & 59.3 & \\
\hline
\end{tabular}

\subsection{Tolerance factor}

To calculate the tolerance factor (TF) it was necessary to determine the idle time (p). The company gives employees 15 minutes for coffee-break in the morning for coffee, 15 minutes for coffee-break in the afternoon, 10 minutes in the early hours and 10 minutes on their return from lunch. A total of 50 minutes at a workload of 8 hours a day, which results in a p of 0.104 and a FT of 1.116.

\subsection{Standard time of operators, activities and overall production process}

The tolerances granted by the company were added to the average time of each activity and each operator (table 5 ) and then the average time of the production process (table 6), resulting in tables 7 and 8 , respectively.

Table 7: Operators' Standard Time

\begin{tabular}{cccccc}
\hline Standard Time (s) & A1 & A2 & A3 & A4 & A5 \\
\hline Operator 1 & 134.1 & 92.2 & 77.0 & 47.1 & 86.4 \\
Operator 2 & 190.0 & 131.4 & 121.6 & 66.0 & 104.0 \\
Operator 3 & 135.5 & 102.4 & 105.1 & 63.4 & 49.0 \\
Operator 4 & 154.0 & 89.1 & 90.0 & 60.0 & 50.4 \\
Operator 5 & 131.7 & 85.0 & 73.7 & 61.6 & 44.0 \\
\hline
\end{tabular}

Table 8: Standard time of activities and production process

\begin{tabular}{ccc}
\hline Activities & ST of operation(s) & OT of overall production process \\
\hline A1 & 149.0 & \\
A2 & 100.0 & 468.4 \\
A3 & 93.3 & \\
A4 & 59.5 & \\
A5 & 66.2 & \\
\hline
\end{tabular}

\subsection{Operators' performance rating}

The performance rating was calculated for each operator in order to compare them with the normal rate of the company. It is worth mentioning that if the operator is above $100 \%$ it means he is slow, if it is below $100 \%$ it is because he is agile and if 
operator is equal to $100 \%$ it means that he is performing his task exactly in the company's average time. The following table represents, in percentage, the performance rating of the operators considering the productive process.

Table 9: Operators' performance rating in percentage

\begin{tabular}{cc}
\hline Operators & Performance rating on the production process \\
\hline Operator 1 & $83 \%$ \\
Operator 2 & $117 \%$ \\
Operator 3 & $87 \%$ \\
Operator 4 & $85 \%$ \\
Operator 5 & $76 \%$ \\
\hline
\end{tabular}

\subsection{Qualitative analysis}

Evaluating the data collected, it was noticed that the factor "Married" was directly related to the factor "Children", so that every married operator had at least one child and the unmarried did not have any. For this reason, one of the factors was removed from the analysis, remaining only the factor "Married". The table below shows the means and standard deviation of each factor level studied, as well as the p-values obtained by ANOVA:

Table 10: Mean, standard deviation and p-value of each factor's level

\begin{tabular}{c|c|c|c}
\hline \multirow{2}{*}{ Factors } & \multicolumn{2}{|c|}{ Mean and standard deviation } & \multirow{2}{*}{ p-value } \\
\cline { 2 - 4 } & Yes/ Complete & No/Incomplete & \\
\hline Married & $483.45 \pm 99.41$ & $445.84 \pm 55.17$ & 0.2891 \\
\hline Offshore & $476.42 \pm 89.25$ & $436.36 \pm 64.14$ & 0.3580 \\
\hline Education & $501.31 \pm 94.36$ & $419.06 \pm 31.61$ & $0.0145^{\star}$ \\
\hline \multicolumn{2}{c}{$\star_{\text {it presented a significant difference with p-value }<0.05}$}
\end{tabular}

*it presented a significant difference with $p$-value $<0.05$

According to ANOVA, only the training factor presented a significant difference, i.e., p-value $<0.05$. Therefore, operators whom have already completed their technical courses in mechanics perform the activities in standard time greater than those that have not yet completed. This result was contrary to expectations, but may be related not to the fact that the academic training interferes with the execution of the activities, but to the fatigue of the work routine, accumulation of tasks, pressure from the top management, among others. Consequently, it is not possible to state the causes that affected the trained operator to perform the activity in a larger standard time and a more detailed study would be necessary. The other factors presented $p$-value $>0.05$, therefore, the hypotheses of equality between the averages were rejected, that is, working on board and being married did not change the standard time. 
DOI: 10.14807/ijmp.v9i5.811

\subsection{Quantitative analysis}

For the study of factors of quantitative levels, the age and time of operator experience were taken into consideration. The number of children was withdrawn from the analysis since the fact of having children does not change the standard time, as already written in item 4.5 .

The correlation analysis identifies a directly proportional relationship (positive correlation: $r=0.54$ ) between the employee's standard time and his age and inversely proportional between the standard time and his experience time (negative correlation: $r=-0,31$ ). With the interpretation of these correlations, it is expected that employees of smaller age and greater time of experience would be preferable because they have shorter operating times.

However, it can be considered that these relations are weak, the latter being even smaller. Then, a linear regression was performed with a first-degree model to identify the cause and effect relationship between these factors and the standard time.

As a result of the analysis of variance for regression, the time of experiment was not significantly ( $p$-value $>0.05$ ) the cause of the variation of the operators' standard time. In contrast, age was statistically significant ( $p$-value $<0.05$ ) with $R^{2}=29.1 \%$. Due to the $\mathrm{R}^{2}$ value obtained being considered low, an adjustment was made for a second-degree model, with results in the table below:

Table 11: $\mathrm{R}^{2}$ values

\begin{tabular}{|c|c|c|c|c|}
\hline Factor (X) & First-degree model & $\mathbf{R}^{2}$ & Second-degree model & $\mathbf{R}^{2}$ \\
\hline $\begin{array}{l}\text { Experience time } \\
\text { Age }\end{array}$ & $\begin{array}{c}Y=-1.79 X+528.46 \\
Y=6.23 X+284.01\end{array}$ & $\begin{array}{c}0.1 \\
0.29\end{array}$ & $Y=1.31 X 2-71.35 X+364.05$ & 0.72 \\
\hline
\end{tabular}

The second-degree model was chosen to represent the data, since it presented higher value of $\mathrm{R}^{2}$ than the first-degree model. This model, represented graphically by a parabola of upwards concave, suggests an optimal value of age so that one has a minimum time. The graph below represents the standard time as a function of age, according to the proposed quadratic model. 


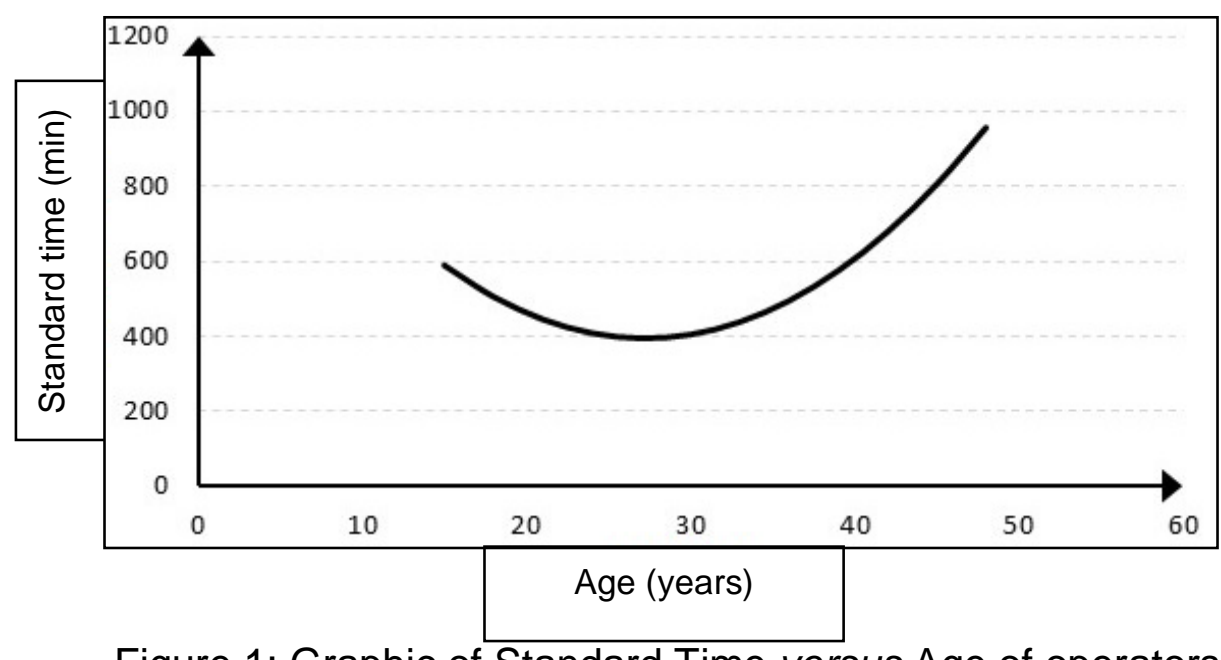

Figure 1: Graphic of Standard Time versus Age of operators

Optimization indicates the most appropriate age to have a shorter standard time is approximately 27 years, which generates an approximate optimum standard time of $393 \mathrm{~min}$.

\section{CONCLUSIONS}

This case study presented the application of time and motion study, in association with the statistical techniques ANOVA and linear regression, in the process of manometer calibration, in the city of Campos dos Goytacazes/RJ.

When comparing the standard time of each operator in relation to the standard time of the company, it was possible to identify which are the slower and faster operators. With the application of ANOVA it was revealed that operators who have already completed their technical courses in mechanics perform the activities in standard time greater than those that have not yet completed.

Also, factors such as working on board and being married do not change the standard time. When performing the Linear Regression, it was verified that the experience time was not significant to influence in the variation of the operators' standard time and that the age was statistically significant, revealing that the age most suitable to have a smaller standard time is approximately 27 years.

For the company in question this information is of extreme importance since it is a service provider and one of the definitions of service is the variability. Thus, the results show the variability among operators. There are two ways in which the 
company can charge an offshore service: per day, operators will board the ship or platform to perform the service for a certain period of time previously established and; for productivity, an equipment inspector goes on board before summoning operators to measure how many equipment there is on board that need calibration.

So, the crew goes aboard without a set date to return and the more equipment the operators calibrate, the higher the profit. According to the Commercial Director, productivity contracts are much more profitable and represent a large part of the contracts performed, so time and motion study revealed a standard time for the calibration of onboard gauges and statistical analyzes revealed the factors which most influence this execution time.

It is suggested that all the employees who works onboard should be trained to reach this standard time and thus lead to greater productivity, where more gauges will be calibrated in a shorter time; more contracts closed in one period; increased reliability due to reduced time staff is on board; and cost reduction. For future research, it is recommended that a greater number of operators must be analyzed, as well as the application in other market segments.

\section{REFERENCES}

AL-SALEH, K. S. (2011) Productivity improvement of a motor vehicle inspection station using motion and time study techniques. Journal of King Saud University Engineering Sciences, v. 23, n. 1, p. 33-41.

AMATO, D. T.; REIS, A. C. (2016) A percepção dos monitores sobre o programa de monitoria do Ensino Superior do CEFET/RJ. Scientia Plena, v. 12, n. 7, p. 1-10.

BARNES, R. M. (2004) Estudo de movimentos e de tempos: Projeto e medida do trabalho. 6 ed. São Paulo: Edgard Blücher LTDA.

CHIAVENATO, I. (2014) Introdução a teoria geral da administração. 9. ed. São Paulo: Manole.

FIGUEIREDO, F. J. S.; OLIVEIRA, T. R. C.; SANTOS, A. P. B. M. (2011) Estudo de tempos em uma indústria e comércio de calçados e injetados Itda. In: ENCONTRO NACIONAL DE ENGENHARIA DE PRODUCAO, 31, Belo Horizonte, Anais..., Belo Horizonte: Enegep, 2011.

GOLBERG, M.; CHO, H. A. (2004) Introduction to Regression Analysis. 1 ed. EUA: WIT Press.

GONÇALVES, J. L. et al. (2014) Estudo de tempo e movimento na etapa de seleção de mudas em um viveiro florestal. Floresta, v. 44, n. 4, p. 647-656.

IBGE. (2017) Agência IBGE Notícias. Disponível em: < https://agenciadenoticias.ibge.gov.br/agencia-sala-de-imprensa/2013-agencia-denoticias/releases/16555-setor-de-servicos-tem-queda-de-0-8-em-julho.html >. 
Access: 17th September, 2017.

JACOBS, F. R.; CHASE, R. B. (2012) Administração de operações e da cadeia de suprimentos. 13 ed. Porto Alegre: McGrawHill.

LOPETEGUI, M. et al. (2014) Time motion studies in healthcare: What are we talking about? Journal of Biomedical Informatics, v. 49, p. 292-299.

MARTINS, P. G.; LAUGENI, F. P. (2015) Administração da produção. 3 ed. São Paulo: Saraiva.

NOVASKI, O.; SUGAI, M. (2002) Mtm como ferramenta para redução de custos: O taylorismo aplicado com sucesso nas empresas de hoje. Revista Produção Online, v. 2, n. 2.

PEINADO, J.; GRAEML, A. R. (2007) Administração da Produção: operações industriais e de serviços. Curitiba: UnicenP.

SANTOS, A. C. S. G. et al. (2015) Estudo de tempos e movimentos no processo de confecção de jalecos. In: ENCONTRO NACIONAL DE ENGENHARIA DE PRODUCAO, 35, Fortaleza, Anais..., Fortaleza: Enegep, 2015.

SILVA, E. L.; MENEZES, E. M. (2005) Metodologia da Pesquisa e Elaboração de Dissertação. 4 ed. Florianópolis: Universidade Federal de Santa Catarina.

SILVA, V. A. A.; GUIMARÃES, A. L.; JÚNIOR VERALDO, L. G. (2014) Aplicação de técnicas de tempos \& métodos em linha de envase de óleos lubrificantes. Revista de Gestão \& Tecnologia, v. 1, n. 2, p. 58-63.

SIMÕES, D.; FENNER, P. T.; ESPERANCINI, M. S. T. (2014) Produtividade e custos do Feller-Buncher e processador florestal em povoamento de eucalipto de primeiro corte. Ciencia Florestal, v. 24, n. 3, p. 621-630. 